\title{
A EXPERIMENTOTECA VAI À ESCOLA: ENSINANDO OSCILAÇÕES E ONDAS ATRAVÉS DE EXPERIMENTOS.
}

\author{
Wagner Muniz Silva ${ }^{1}$, JeAn DuArte e Silva $^{2}$, Letícia Francisca Almeida ${ }^{3}$, Marcionílio teles \\ DE OLIVEIRA SILVA ${ }^{4}$, ANA RITA PEREIRA ${ }^{5}$
}

Departamento de Física, Campus Catalão da Universidade Federal de Goiás

\author{
wagnerorz@yahoo.com.br ${ }^{1}$ jeansilvapder@gmail.com², leticia_leisy@hotmail.com ${ }^{3}$, \\ mteles2009@gmail.com ${ }^{4}$, anaritapr@gmail.com ${ }^{5}$
}

\begin{abstract}
This work shows results from an extension project accomplished at the Colégio Estadual Abrahão André, where we used experiments like a teaching strategy, together with traditional classes, in order to present and to discuss with the students the concepts and theories about physical phenomena. The activities were performed by UFG undergraduated students in teaching physics in two classes of the high school second grade attending the discipline "Topics of Physics", that allowed the project development without to interference on the contents which are regulars, under care of the high school instructors and the UFG coordinators of the project. Interactive lessons were presented, jointly with theoretical and experimental activities, to discuss with the students the concepts about oscillations and waves, by considering always the students' spontaneous conceptions and by emphasizing the relationship between Science, Technology, Society, and environment (CTSA in Portuguese). By means of observations, discussions in the classroom and applications of questionnaires, we analyzed how the students build up and develop knowledge and how the experimental activities contribute to the students' learning, causing themselves to have a more clear vision about Physics and to be able to associate it to their daily lives.
\end{abstract}

Keywords ---Experiments, High School, oscillations and waves.

Resumo - Este trabalho apresenta resultados de um projeto de extensão realizado no Colégio Estadual Abrahão André, onde se utilizou a experimentação como estratégia de ensino, combinada com as aulas tradicionais, para apresentar e discutir com os alunos os conceitos e teorias dos fenômenos físicos. As atividades foram realizadas por licenciandos em Física da UFG em duas turmas de segunda série do Ensino Médio que cursavam a disciplina "Tópicos de Física", o que possibilitava o desenvolvimento de projetos sem interferir nos conteúdos regulares, sob a supervisão da professora da escola e dos coordenadores do projeto na UFG. Foram apresentadas aulas interativas, com atividades teóricas e experimentais, para discutir com os estudantes os conceitos de oscilações e ondas, sempre considerando as concepções espontâneas dos alunos e enfatizando a relação Ciência, Tecnologia, Sociedade e Ambiente (CTSA). Por meio de observações, discussões em sala e aplicação de questionários, analisou-se como os estudantes constroem e desenvolvem o conhecimento e como as atividades experimentais contribuem para o aprendizado dos estudantes, fazendo com que os mesmos obtenham uma visão mais clara da Física e consigam associa-la ao seu cotidiano.

Palavras-chave—Experimentação, Ensino Médio, Oscilações e ondas.

\section{Introdução}

Os estudantes já chegam ao Ensino Médio carregando uma longa bagagem educacional adquirida nas series anteriores, mas cada vez mais tem sido comentado sobre o desinteresse generalizado dos alunos, em particular em relação à disciplina de Física, que sido vista com sentimento de inutilidade e considerada uma ciência complicada, que exige muito esforço e dedicação por parte do aluno para seu aprendizado. Mesmo considerando a importância da física para a sociedade, em geral isso não é apresentado na sala de aula, cujas aulas raramente associam os fenômenos físicos com o cotidiano do estudante, sendo que as aulas são consideradas maçantes, com muitas fórmulas matemáticas a serem decoradas e a resolução repetitiva de inúmeros exercícios descontextualizados. Logo, como a maior preocupação é a aprovação, a Física é vista como um problema a ser superado para concluir o ensino médio por uma parcela significativa de estudantes.

São inúmeras as causas para os problemas enfrentados pelo ensino de Física, tais como: formação inadequada dos professores de Física (falta licenciados em Física), ausência de professores para ministrarem as aulas de Física (em várias escolas os alunos ficam meses sem aulas), condições de trabalho bastante precárias com baixos salários e uma infraestrutura das escolas bastante deficitária (na maioria das escolas não existe laboratórios e aulas experimentais), e no fim tudo isso resulta numa máformação e um enorme desinteresse dos estudantes.

Embora grande parte dos docentes de Física do Ensino Médio reconheça a importância de atividades experimentais para o ensino de Física, o número de professores que utilizam aulas práticas ainda é muito pequeno, e em geral as aulas são ministradas 
apenas utilizando o quadro negro e giz. Esta situação reflete a desvalorização do professor e as condições precárias em que se encontram as entidades de ensino [CUNHA et al., 2010].

Considerando toda essa problemática, o projeto A Experimentoteca de Física vai até a Escola procurou inovar o ensino tradicional de Física utilizando a experimentação como estratégia para ensinar oscilações e ondas, com o objetivo de despertar o interesse dos alunos e verificar como estes entendem e/ou assimilam os conteúdos teórico-experimentais de Física. As atividades foram realizadas na disciplina "Tópicos de Física", ministrada em uma aula semanal durante o ano letivo de 2013, nas duas turmas da segunda série do ensino médio, do período matutino, do Colégio Estadual Abrahão André, e foram conduzidas pelo grupo responsável, utilizando, além das aulas tradicionais, multimídias e apresentação de experimentos. Alguns experimentos foram demonstrativos e outros foram interativos, onde os estudantes tiveram que coletar e analisar os dados obtidos. $\mathrm{O}$ projeto foi avaliado, qualitativamente, com base no rendimento dos alunos nas avaliações e nas respostas dos mesmos em questionários de acompanhamento realizados ao longo do semestre.

\section{Metodologia}

De acordo com Lopes (2004), "Conhecer as características dos alunos é uma tarefa essencial para preparar o Ensino-Aprendizagem de Física”. Assim, com o intuito de analisar e compreender qual a percepção que os alunos têm da Física, o projeto iniciou-se com a aplicação de um questionário para identificar como os alunos veem a Física e as aulas de Física. E ao longo do ano foram aplicados outros questionários sobre os conteúdos discutidos e os conhecimentos prévios dos alunos (questionários de estilo pré-teste e de pós-teste). Estes serviram de base para uma analise qualitativa do processo de ensino-aprendizagem.

Após analisar a "visão" que os alunos tem da Física, foram iniciadas as atividades programadas antecipadamente com a professora de Física. Em geral, estas atividades iniciavam verificando as concepções espontâneas dos alunos sobre determinado fenômeno físico, em seguida tinha a apresentação de um experimento, de uma simulação, de um vídeo ou da teoria envolvida, e após momentos de diálogos para possibilitar aos alunos elaborar e criar questões relativas ao tema e discuti-las com os colegas.

Os temas trabalhados com os estudantes foram os conteúdos envolvendo os conceitos de oscilações e ondas e os experimentos apresentados foram os seguintes: Sistema Massa-Mola; O Pêndulo Simples; O Microfone sem Fio, A Mola Maluca e Cordas Vibrantes.

\section{Resultados e análise}

O projeto iniciou verificando a percepção dos estudantes em relação à disciplina Física e sobre as aulas de Física. Para isso foi utilizado, como instrumento de coleta de dados, o questionário desenvolvido por Menegotto e Rocha Filho (2008), ao qual foram acrescentadas questões abertas para identificar os conhecimentos prévios dos alunos sobre os conteúdos a serem trabalhados. Abaixo é apresentada a $1^{\mathrm{a}}$ parte do questionário e os números à direita correspondem ao numero de alunos que apontaram cada alternativa. Os alunos que responderam ao questionário foram orientados a não se identificarem. Nas duas turmas 21 alunos responderam ao questionário e estes alunos tem uma média de idade de 16,7 anos.

A primeira parte do questionário constituía de afirmações em que os estudantes apontavam desde se concordavam totalmente até discordavam totalmente, apresentados assim: 1) O que você pensa das afirmações abaixo (Marque uma alternativa sendo que A - Concordo totalmente; B - Concordo parcialmente; C - Sem opinião; D - Discordo parcialmente e $\mathbf{E}$ - Discordo totalmente).

\begin{tabular}{|l|c|c|c|c|c|}
\hline & A & B & C & D & E \\
\hline $\begin{array}{l}\text { Os assuntos estudados pela } \\
\text { disciplina de Física são inte- } \\
\text { ressantes e importantes para o }\end{array}$ & $\mathbf{1 1}$ & $\mathbf{9}$ & $\mathbf{0}$ & $\mathbf{1}$ & $\mathbf{0}$ \\
$\begin{array}{l}\text { desenvolvimento da socieda- } \\
\text { de. }\end{array}$ & & & & \\
\hline $\begin{array}{l}\text { Estudo Física apenas para } \\
\text { passar de ano. }\end{array}$ & $\mathbf{4}$ & $\mathbf{5}$ & $\mathbf{1}$ & $\mathbf{3}$ & $\mathbf{8}$ \\
\hline $\begin{array}{l}\text { Não vejo aplicação prática do } \\
\text { que aprendo nas aulas de Físi- } \\
\text { ca. }\end{array}$ & $\mathbf{1}$ & $\mathbf{1}$ & $\mathbf{9}$ & $\mathbf{5}$ & $\mathbf{5}$ \\
\hline $\begin{array}{l}\text { Sinto prazer em desenvolver } \\
\text { as atividades na disciplina de }\end{array}$ & $\mathbf{5}$ & $\mathbf{6}$ & $\mathbf{7}$ & $\mathbf{1}$ & $\mathbf{2}$ \\
\begin{tabular}{|l} 
Física. \\
Para mim, estudar Física é \\
perda de tempo.
\end{tabular} & $\mathbf{0}$ & $\mathbf{0}$ & $\mathbf{3}$ & $\mathbf{3}$ & $\mathbf{1 5}$ \\
\hline $\begin{array}{l}\text { Sinto-me perdido nas aulas de } \\
\text { Física. }\end{array}$ & $\mathbf{3}$ & $\mathbf{9}$ & $\mathbf{1}$ & $\mathbf{4}$ & $\mathbf{4}$ \\
\hline $\begin{array}{l}\text { Percebo a importância e apli- } \\
\text { cação da Física nas minhas }\end{array}$ & $\mathbf{7}$ & $\mathbf{4}$ & $\mathbf{7}$ & $\mathbf{3}$ & $\mathbf{0}$ \\
\hline \begin{tabular}{l} 
atividades diárias. \\
\hline Estudo Física com prazer.
\end{tabular} & $\mathbf{0}$ & $\mathbf{6}$ & $\mathbf{7}$ & $\mathbf{4}$ & $\mathbf{4}$ \\
\hline $\begin{array}{l}\text { Acho difícil aprender Física. } \\
\text { A Física desperta a minha }\end{array}$ & $\mathbf{9}$ & $\mathbf{6}$ & $\mathbf{1}$ & $\mathbf{2}$ & $\mathbf{0}$ \\
\hline $\begin{array}{l}\text { curiosidade. } \\
\text { Sinto-me desconfortável só de } \\
\text { ouvir a palavra Física. }\end{array}$ & $\mathbf{2}$ & $\mathbf{1}$ & $\mathbf{5}$ & $\mathbf{3}$ & $\mathbf{1 0}$ \\
\hline $\begin{array}{l}\text { Aprendo Física com facilida- } \\
\text { de. }\end{array}$ & $\mathbf{0}$ & $\mathbf{3}$ & $\mathbf{4}$ & $\mathbf{4}$ & $\mathbf{1 0}$ \\
\hline $\begin{array}{l}\text { Não vejo nada interessante nas } \\
\text { aulas de Física. }\end{array}$ & $\mathbf{2}$ & $\mathbf{1}$ & $\mathbf{2}$ & $\mathbf{5}$ & $\mathbf{1 1}$ \\
\hline $\begin{array}{l}\text { Gosto muito de estudar Física. } \\
\text { 0 }\end{array}$ & $\mathbf{8}$ & $\mathbf{6}$ & $\mathbf{3}$ & $\mathbf{4}$ \\
\hline
\end{tabular}

Em relação às questões abertas verifica-se que entre os assuntos que os alunos gostariam de aprender, astronomia ainda é o assunto mais citado, mas teve alunos que citaram "Estudar mais gráficos é um modo mais fácil pra mim aprender", o que evidencia a 
necessidade de se adotar diferentes estratégias e metodologias de ensino.

Quanto às dificuldades encontradas foi citado de forma recorrente o uso das muitas fórmulas, ou seja, entender a linguagem matemática é um problema: "Tem umas contas dificeis, tem umas coisas que entendo outras não", "Tenho dificuldade em fazer exercícios de física", "Não tenho facilidade para aprender", "As formulas as vezes são muito complicada, uma vez que tem exercícios que usa mais de 3 formulas complicadas"e "Não tenho dificuldade consigo pegar a matéria rápido". De forma que, em geral, a física ainda é vista como um conjunto de expressões matemáticas complicadas e de difícil entendimento pela maioria dos alunos.

Outro ponto citado pelos alunos é a dificuldade em compreender a linguagem usada pela física, como podemos ver nas palavras de alguns alunos: "Não, as vezes acho que estão falando em inglês", "Sim sabe como ministrar uma aula", "Às vezes sim”, "Não entendo muito. Porque são cálculos, números demais...", mas em geral os alunos gostam da didática adotada pelo professor de física.

Porém, apesar dos alunos gostarem dos professores e da forma de avaliação a que são submetidos, que em geral, são provas bimestrais, e para ajudar são considerados os cadernos dos alunos, trabalhos, comportamento, existem criticas do tipo: "Não acho o modo de aplicação da prova justa, por que muitos alunos colam pelo celular, trocam as provas, etc. Os alunos que se esforçam são muito injustiçados". Em relação a avaliação, no estado de Goiás existe recuperação paralela a cada bimestre e as avaliações devem incluir trabalhos e provas, e assim muitos professores para "fugir" dessa recuperação atribuem nota por comportamento, caderno, trabalho para que os alunos fiquem na média 5,0. De forma que às vezes o que menos é avaliado é se os alunos aprenderam os conteúdos ministrados nas aulas.

Em relação a oscilações as respostas foram: "Um movimento que fica oscilando", "tudo que se move", "não sei", "um movimento que oscila". E sobre ondas: "A luz, não sei, só nos celulares”, "ondas são movimentos mecânicos ou eletromagnéticos. Sim. Luz, celular, som...", "Sim ondas sonoras da voz das pessoas". Nestas questões a maioria dos alunos não respondeu, porém observou-se que alguns alunos têm noções prévias sobre estes temas, o que enfatiza o fato de o aluno não é uma tábula rasa.

Após os questionários para verificar a percepção dos alunos em relação a Física, foram iniciadas as atividades que discutiam os conteúdos programáticos de oscilações e ondas. Primeiramente foi estudado o sistema Massa-Mola através de um experimento que consistia numa mola suspensa com um peso na ponta. Os alunos analisaram o comportamen- to da mola colocando pesos diversos e observando a distensão da mola. O objetivo dessa atividade era possibilitar aos alunos aprender como realizar medidas, coletar dados num laboratório e analisar os resultados, além de discutir com os mesmos a Lei de Hooke. Com o experimento os alunos aprenderam a medir grandezas físicas diretas e, com o gráfico, determinar a constante da mola; analisar o comportamento estático e dinâmico de um sistema massamola; verificar o comportamento de uma mola variando a força aplicada, ou seja, verificar uma aplicação direta da Lei de Hooke:

$$
F=-k x
$$

A aula foi dividida em duas partes: a primeira discutiu a teoria envolvida abordando a Lei de Hooke e a construção de gráficos. Já a segunda parte foi experimental, sendo os alunos divididos em grupos e cada grupo recebeu um "kit" para realizar o experimento, coletar os dados, construir o gráfico e obter a constante da mola graficamente. Na sala de aula foram encontradas algumas adversidades como a falta de espaço ou mesmo o calor. Em cada turma os alunos foram divididos em 6 grupos, e cada um recebiam um roteiro acerca da atividade a ser desenvolvida. Ao longo dessa atividade foi observado que a maior dificuldade encontrada pelos alunos foi em relação a elaboração e análise de gráficos e também em associar a teoria a prática. Mas os alunos superaram os obstáculos e participaram ativamente, e ficaram satisfeitos com os resultados obtidos no final.

A outra atividade, também realizada em grupo e envolvendo duas partes, teoria e prática, teve por objetivo discutir com os alunos os conteúdos envolvendo o Pêndulo Simples. Os alunos obtiveram experimentalmente diferentes períodos de oscilação de um pêndulo e utilizaram estes dados para calcular o valor da aceleração da gravidade local. Para um melhor entendimento dos conteúdos discutidos foram revisados os conceitos de diagrama de corpo livre e alguns tópicos de geometria analítica. Os alunos utilizaram a equação abaixo para determinar o valor de g:

$$
T=2 \pi \sqrt{\frac{l}{g}}
$$

Em seguida comparam com o valor teórico da aceleração da gravidade, e como obtiveram um valor diferente do valor de $9,8 \mathrm{~m} / \mathrm{s}^{2}$, foi realizada uma discussão sobre o porquê das discrepâncias nos valores obtidas num experimento e os valores teóricos adotados nos livros, e também sobre a importância de se saber qual é o grau de confiabilidade de um resultado. 
Foram também realizados experimentos: Microfone sem fio, mola-maluca, Cordas vibrantes. Estes experimentos foram realizados de forma demonstrativa, onde fizemos uma aula dinâmica para repassar todo o conteúdo envolvendo os conceitos de oscilações e ondas. $\mathrm{O}$ microfone sem fio consistia em duas garrafas cortadas e amaradas as extremidades de um barbante de 5 metros de comprimento, e este experimento foi utilizado para discutir os conceitos de propagação de uma onda sonora.

Já a mola-maluca é um brinquedo de criança que pode ser utilizado para demonstrar o comportamento das ondas transversais e longitudinais, este causou espanto aos alunos, pois algo muito simples mostrou aos mesmos, de forma clara e eficaz, cada detalhe de como uma onda se propaga.

E por fim com o experimento das cordas vibrantes construído com um barbante e um motor de aquário, mostrou aos alunos as diferentes grandezas envolvidas num movimento ondulatório, tais como: período, amplitude e comprimento de onda. Esses conceitos envolvendo um movimento harmônico foram também utilizados para discutir a relação entre a Física e a Música, mostrando como vibrações periódicas em harmonia geram notas musicais e como isso é utilizado na construção e funcionamento dos instrumentos musicais. Este assunto despertou grande interesse e teve grande participação dos alunos, pois na sala havia alguns músicos, que ficaram entusiasmados por conseguirem aprender algo mais acerca do funcionamento de seus instrumentos musicais.

Assim, utilizando estes experimentos, os alunos puderam observar que a física dos livros didáticos, cheia de fórmulas matemáticas, é a mesma com a qual eles se deparam durante a realização de quase todas as atividades em seu dia-a-dia.

\section{Conclusão}

Em relação às atividades desenvolvidas observou-se um aumento considerável no nível de entendimento dos conteúdos ministrados, tendo sido observado uma melhora no rendimento dos alunos, inclusive com aumento das notas obtidas ao longo do semestre. Foi também observado um maior interesse e envolvimento dos alunos em participar das atividades propostas, alunos que inicialmente foram bastante resistentes e sem interesse, no final do ano já participavam plenamente das atividades e questionavam sobre a continuidade do projeto este ano.

Este comportamento reforça ainda mais a necessidade de uma maior articulação entre a teoria e prática no desenvolvimento do conteúdo ministrado em sala de aula. Mostra, também, que as atividades experimentais consistem numa ferramenta bastante eficaz, fugindo da rotina das aulas tradicionais, com quadro e giz, tendo apresentado resultados bastante satisfatórios.

Um detalhe observado foi que existem diferenças entre as turmas, sendo uma turma mais interessada que a outra, com alunos mais focados e participativos, e com notas maiores em relação ás avaliações realizadas.

Em relação às respostas dos alunos nos questionários observa-se um descompasso entre a Física apresentada nos livros escolares e a estudada pelos alunos na escola. Em geral estes tendem a associar "Física = matemática aplicada", o que pode prejudicar a construção dos saberes e conhecimento dos fenômenos físicos. E como educadores temos que buscar soluções para essas questões, e os professores devem buscar formas de relacionar os conteúdos curriculares com o cotidiano dos alunos, inclusive utilizando os meios de comunicação e a experimentação. Se não houver mudanças no processo de ensino-aprendizagem da Física, continuará valendo a ideia de que os conhecimentos físicos são coisas que "nunca usaremos em nossa vida.", que "são pura matemática", e que "não são aplicados no meio em que vivemos", como foi colocado por alguns alunos no questionário inicial. Mas quando são colocados em contato com outras estratégias de ensino que associa a Física com o que eles fazem cotidianamente, observa-se que os alunos apresentam um maior interesse, verificando que seu aprendizado é importante para a sua formação pessoal e profissional.

O que foi observado com este projeto é que os alunos sentem prazer nas atividades que demonstrem os conceitos dos fenômenos físicos, mas muitas vezes a linguagem utilizada pelo professor não torna esses conceitos claros, ou seja, os conteúdos não são abordados de forma a favorecer a reflexão e interação com o objeto de aprendizagem, o que pode provocar a rejeição de muitos pelo processo de aprendizagem de física.

Um ponto positivo, a ser ressaltado, foi a receptividade da escola em receber este projeto, em especial por parte dos alunos das salas envolvidas. Houve também uma cobrança, por parte dos alunos das outras séries do ensino médio, de que o projeto fosse estendido às salas deles. Isto deixou a equipe muito feliz e neste ano o projeto deve ser mais abrangente, principalmente porque haverá na escola o envolvimento de um equipe do Programa Institucional de Bolsas de Iniciação a Docência (PIBID), o que permitirá aumentar o numero de atividades desenvolvidas. 


\section{Agradecimentos}

A professora Monica da Cunha Alves por ter aceitado a equipe em suas aulas e ter colaborado muito para o desenvolvimento e sucesso do projeto.

Aos programas de bolsas da Universidade Federal de Goiás: PIBIC, PROBEC e PROCOM.

Ao CNPQ e CAPES pelo apoio financeiro.

Ao Colégio Estadual Abrahão André - Catalão GO.

\section{Referências}

[1] CUNHA, T. F.; AVELAR, F. P. , DUTRA, J. C. B.; SILVA, J. D.; PEREIRA, A. R.; NETO, F. A.; DUARTE, J. P.; FILHO, M. B, CONPEX - Goiânia-GO Oficinas Experimentais de Física no Colégio Estadual Abrahão André - Uma Ação do Programa PIBID., p.4385-4389, 2010 .

[2] LOPES, B. J., Aprender e Ensinar Física. Fundação Calouste Gulbenkian, (2004).

[3] MenegotTo, J. C., ROCHA Filho, J. B., Atitudes de estudantes do ensino médio em relação à disciplina de Física. Revista Electrónica de Enseñanza de las Ciencias, Vol. 7, $N^{\alpha_{2}}$ (2008). 